\title{
Simultaneous ocean surface current and wind vectors retrieval with squinted SAR interferometry: Geophysical inversion and performance assessment
}

\author{
Martin Adrien C.H. ${ }^{1,{ }^{*}}$, Gommenginger Christine P. ${ }^{1}$, Quilfen Yves ${ }^{2}$ \\ ${ }^{1}$ National Oceanography Centre, Marine Physics and Ocean Climate Division, Southampton, UK \\ ${ }^{2}$ IFREMER, Univ. Brest, CNRS, IRD, Laboratoire d'Océanographie Physique et Spatiale (LOPS), Brest, \\ France \\ * Corresponding author : Adrien C.H. Martin, email address : admartin@noc.ac.uk
}

\begin{abstract}
:
Simultaneous measurements of ocean surface current and wind vectors at the ocean submesoscale $(O$ [1-10 km]) are needed to improve our understanding of upper ocean mixing, air-sea interactions, ocean biophysical processes and large-scale oceanic transports. A new satellite mission concept called SEASTAR aims to do just that. The concept is a Ku-band along-track interferometric Synthetic Aperture Radar (SAR) system with two squinted beams pointing $\pm 45^{\circ}$ from broadside and incidence angles around $30^{\circ}$. The paper presents an inversion strategy to retrieve simultaneously ocean surface current and wind vectors and reports on the performance obtained with different wind/current conditions and instrument configurations. Results are based on numerical simulations using a Bayesian approach and existing geophysical model functions (GMFs) of the microwave Normalized Radar Cross Section (NRCS) and Doppler shift.

Using the baseline two-look instrument configuration and realistic instrument noise figures (radiometric resolution: $\mathrm{kp}=5$ and $12 \% ; \Delta \mathrm{df}=2$ and $5 \mathrm{~Hz}$ ), the root-mean square errors (RMSE) of the retrieved current and wind vectors are typically better than $\left[0.1 \mathrm{~m} / \mathrm{s}, 10^{\circ}\right]$ for current and $\left[0.5 \mathrm{~m} / \mathrm{s}, 5^{\circ}\right]$ for wind. This inversion setup yields four ambiguous solutions within a current range of $\sim 1 \mathrm{~m} / \mathrm{s}$. The addition of dual polarization $(\mathrm{VV}, \mathrm{HH})$ capability helps to discriminate these ambiguities. The retrieval performance depends weakly on geophysical parameters such as wind speed, current velocity or current direction, but is sensitive to wind direction because of its strong effect on current retrieval through the wind-wave induced artifact surface velocity (WASV). Larger retrieval errors are obtained when the wind is aligned with one of the antenna line-of-sight (LoS) directions, although errors remain typically below $[0.2 \mathrm{~m} / \mathrm{s}$, $\left.25^{\circ}\right]$ for current and $\left[0.5 \mathrm{~m} / \mathrm{s}, 15^{\circ}\right]$ for wind. Improving the retrieval performance regardless of wind direction could be achieved either with lower noise figures on $\sigma 0$, or with higher incidence angles, or by including an additional third-look direction in azimuth (e.g. to achieve a configuration similar to Metop/ASCAT scatterometers) as per the SEASTAR mission concept submitted to EE10.
\end{abstract}




\section{Highlights}

- Dual squinted beam ATI SAR system achieve simultaneous current and wind retrieval. $\rightarrow$ Retrieval RMSE typically below $\left[0.1 \mathrm{~m} / \mathrm{s}, 10^{\circ}\right]$ for current, $\left[0.5 \mathrm{~m} / \mathrm{s}, 5^{\circ}\right]$ for wind. Performance degraded when wind blowing parallel to one antenna's line-of-sight. Wind direction knowledge is key for correct current vector retrieval.

Keywords : Ocean surface current vector ; Ocean wind vector ; Doppler ; Scatterometer ; SAR ; Alongtrack interferometry 


\section{Introduction}

Ocean surface current and wind vectors observations at the ocean submesoscale $(\mathrm{O}[1-10 \mathrm{~km}])$ are needed as these features play a key role in ocean mixing, air-sea interactions, ocean biophysical processes and large-scale oceanic transports Martin \& Richards 2001; Lapeyre \& Klein 2006; Lévy et al. 2010; Sasaki et al. 2014].

High-resolution ocean surface winds can be derived from active microwave Synthetic Aperture Radar (SAR) that have spatial resolutions of the order of a few tens of meters (e.g. Monaldo et al. [2013]). SAR systems measure the Normalized Radar Cross Section (NRCS) of the surface which is linked to the surface roughness and over the ocean to the wind vector. NRCS depends on wind speed and on the relative azimuth angle between the wind direction and the antenna look direction. Standard SAR systems have antennas with a single look direction, which make the wind inversion an under-constrained problem (e.g. Portabella [2002]). To overcome this, additional information about wind direction is usually obtained either from numerical weather prediction (NWP) output, scatterometer data or from visible streaks or shadowing in the SAR image. Whilst promising, these methods are not universally applicable and, most notably, are problematic in coastal areas where NWP do not resolve local effects, scatterometers cannot retrieve wind closer than $\sim 10 \mathrm{~km}$ from the coast, and wind streaks and shadowing are not always detectable or discriminable from non-wind related effects.

High-resolution ocean surface radial velocity measurements can also be obtained with SAR systems, using either the Doppler Centroid Anomaly (DCA) method e.g. Chapron et al. [2005] or Along-Track Interferometry (ATI) e.g. Romeiser et al. [2014]. In both cases, the system measures Preprint submitted to Remote Sensing of Environment

July 4, 2018 
the Doppler shift induced by the ocean surface motion in the line-of-sight (LoS) direction perpendicular to the platform track. Ocean surface radial velocity thus relates to the motion of the surface in only one direction. The motion sensed by the microwave radar (after correcting for navigation and geometry) has two components: the total ocean surface current - consisting of all currents contributing to actual horizontal transport of water - and an unwanted measurement bias associated with wind-waves (known as windwave induced artifact surface velocity - WASV; see [Martin et al. 2016b]). The WASV is understood to be mainly caused by the phase velocity of the surface scatterers responsible for the microwave backscatter (e.g. Bragg waves) and the effect of the orbital motion of longer ocean waves (see Fig. 6 in Chapron et al. 2005]).

A new satellite mission concept, called SEASTAR, is being proposed to measure simultaneously both ocean surface current vectors and wind vectors at high-resolution $(1 \mathrm{~km})$. The concept, that derives from the original Wavemill concept [Buck 2005], comprises a Ku-band dual beam along-track interferometric SAR system with two squinted azimuth look directions $\pm 45^{\circ}$ from broadside and incidence angles centered on $30^{\circ}$. The geometry is similar to the Seasat-A Scatterometer System (SASS) [Jones et al. 1982 with $90^{\circ}$ separation in azimuth between the two antennas look direction. The concept has been demonstrated with an airborne proof-of-concept experiment [Martin et al. 2016b] and validation results against independent ocean surface current measurements from HF radar can be found in Martin \& Gommenginger [2017.

The aim of this paper is to introduce the geophysical inversion for simultaneous current and wind retrieval and to quantify the retrieval performance for current and wind vectors with the proposed concept and realistic instrumental noise figures. Using numerical simulations, the performance is estimated for a wide range of wind and current conditions and different instrument configurations (including choice of squint angle, incidence angle, single/dual polarization and noise figure). The approach adopted here is purely through numerical simulations and does not involve any observational data. The present work builds on initial results from the WaPA (Coastal and Ocean Surface Currents Mission Study: Wavemill Product Assessment) study funded by the European Space Agency Quilfen \& Chapron 2015 and was extended with the support of the UK Centre for Earth Observation Instrumentation and Space Technology (CEOI-ST) Martin et al. 2016a. 
The paper is arranged as follows. Section 2 presents the Geophysical Model Functions (GMFs) for NRCS and WASV. The method for the geophysical inversion, including the cost function definition and the retrieval simulations, is presented in Section 3. The values of the cost function for typical setup are presented in Section 4. The retrieval performance in different geophysical conditions and for different instrument configurations is respectively presented in Section 5 and 6. Results are discussed in Section 7 and the paper closes with conclusions in Section 8.

\section{Geophysical Model Functions datasets}

SEASTAR observables consist of the Normalized Radar Cross Section (NRCS or $\sigma^{0}$ ) and the interferometric phase $(d \phi)$ in two squinted directions and one or more polarizations (i.e. 4 observables for each polarization). Since there is a direct relation between the interferometric phase (Doppler phase shift) and the Doppler frequency shift, $d f$, (e.g. Graber et al. [1996]), in this paper unless specified otherwise, the Doppler shift is expressed in terms of the more commonly used Doppler frequency shift.

The geophysical model functions (GMFs) for the Normalized Radar Cross Section (NRCS or $\sigma^{0}$ ) and Doppler frequency shift $(d f)$ at Ku-band are described in the next sections. For both GMFs, the wind vector $\left(\boldsymbol{u}_{\mathbf{1 0}}\right)$ and speed $\left(u_{10}\right)$ is understood as wind relative to the moving ocean surface and not the absolute wind relative to the Earth, i.e. $\boldsymbol{u}_{\mathbf{1 0}}-\boldsymbol{c}$, where $\boldsymbol{c}$ is the ocean surface current vector. The azimuth angle refers to the wind direction relative to the radar azimuth look angle. An azimuth angle of $0^{\circ}$ is for the upwind direction, i.e. wind is blowing toward the radar antenna.

\subsection{KuMod: Ku-band NRCS GMF}

The GMF for the NRCS at Ku-band is taken from NSCAT WWentz \& Smith 1999 and is referred to as KuMod. The dependences of $\sigma^{0}$ on incidence angle, wind speed and azimuth angle are presented in Figure 1 1 -left for VV (blue) and $\mathrm{HH}$ (red) polarizations. First order effects on $\sigma^{0}$ are the incidence angle and the wind speed (fig. 1 - a, c). At a given incidence angle, $\sigma^{0}$ is driven by the magnitude of the wind speed (fig. 1 - c) with a weak modulation (20\%) with wind direction (fig. 1 -e). $\sigma^{0}$ is strongest when the radar look direction is aligned with the wind direction (upwind and downwind) and weakest when the look direction is perpendicular to the wind (crosswind). 


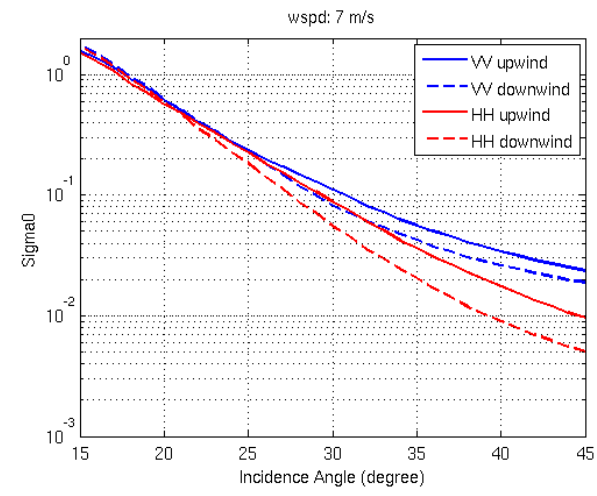

(a)

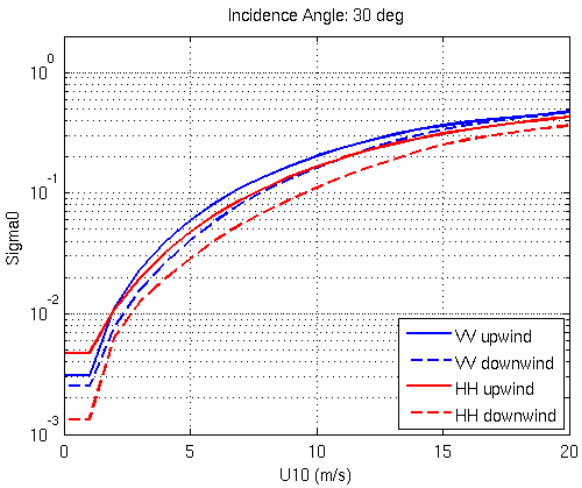

(c)

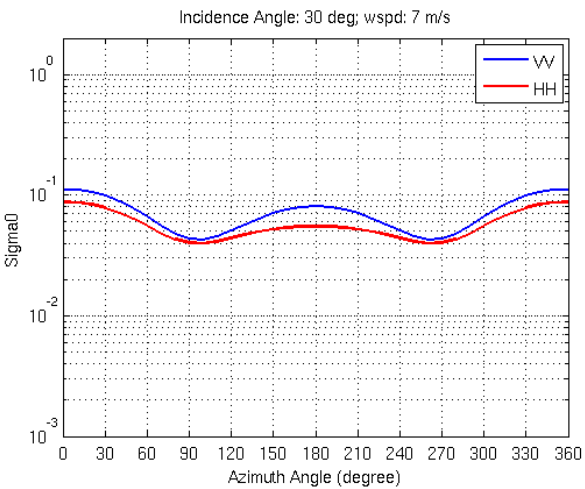

(e)

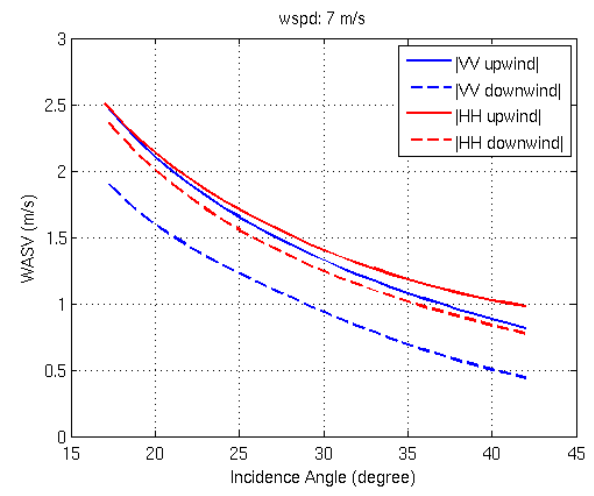

(b)

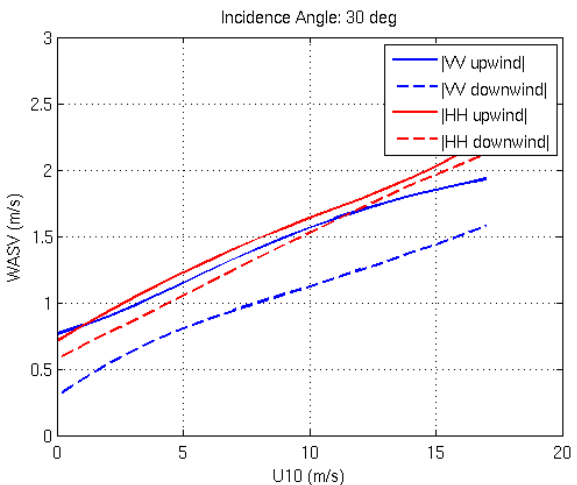

(d)

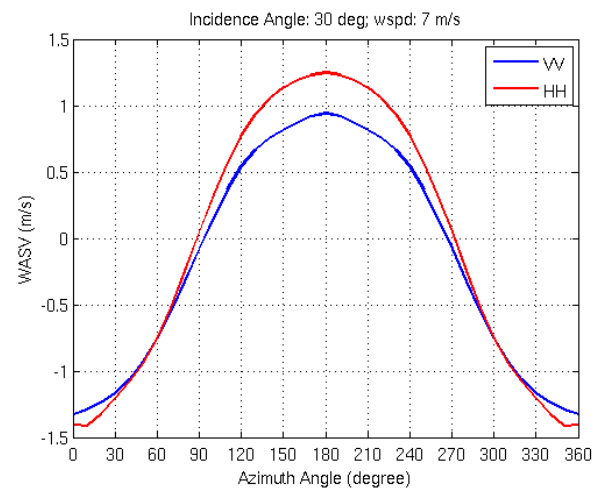

(f)

Figure 1: Geophysical Model Functions (GMFs) for (left) the NRCS (or $\sigma^{0}$ ) at Ku-band [Wentz \& Smith 1999] and (right) the Wind-wave Artefact Surface Velocity (WASV) at Ku-band scaled from the C-DOP model [Mouche et al. 2012. GMF as function of (top) incidence angles for a wind speed of $7 \mathrm{~m} / \mathrm{s}$; (middle) wind speed for an incidence angle of $30^{\circ}$; (bottom) relative wind direction to the antenna (upwind at $0^{\circ}$ ) for an incidence angle of $30^{\circ}$ and a wind speed of $7 \mathrm{~m} / \mathrm{s}$. Blue (red) color is respectively for the $\mathrm{VV}$ $(\mathrm{HH})$ polarization. The plain (dashed) lines in top and middle plots are respectively for upwind (downwind) conditions. 
For incidence angles above $25^{\circ}, \sigma^{0}$ at different polarization shows different behavior with wind speed, indicating that there is little to be gained from multiple polarization at smaller incidence angles (i.e. closer to nadir) (fig. 1-a). The same figure also shows that $\sigma^{0}$ reduces rapidly with increasing incidence angle, particularly for $\mathrm{HH}$ polarization.

Note that, having been developed for scatterometry, this GMF represents the average behavior of $\sigma^{0}$ at the implicit spatial scale typical of scatterometers, namely of few tens of $\mathrm{km}$. At moderate incidence angles, other geophysical effects can modulate the short scale ocean roughness responsible for the backscatter and can also affect $\sigma^{0}$. Modulation by ocean currents, sea state spectrum, bathymetry or wave breaking will all have secondary effects on $\sigma^{0}$ Quilfen et al. 2001, 2004, but are not included here.

\subsection{KuDop: Ku-band Doppler frequency shift GMF due to wind-wave}

The GMF used to estimate the Doppler frequency shift is based on the Envisat C-band C-DOP model [Mouche et al. 2012]. The C-DOP model was derived from a global dataset of Envisat/ASAR observations collocated with ECMWF wind vectors, and gives an expression to estimate the average Cband Doppler frequency shift as a function of wind speed, wind direction and incidence angle. As a global average, C-DOP thus represents the contribution to the Doppler shift by wind-waves. By construction C-DOP includes the wave contribution to the Doppler shift from the full wave spectrum but secondary effects such as swell, bathymetry, wind/wave/current interactions are not included in this statistical average relationship.

The KuDop GMF consists of the C-band C-DOP model [Mouche et al. 2012 after adapting it to Ku-band by frequency scaling of $13.6 / 5.3=2.6$. The validity of frequency scaling is supported by theoretical arguments [Fois et al. 2015] and was established in [Martin et al. 2016b] on the basis of the similarity observed between the X-band Wavemill proof-of-concept airborne data and the Envisat C-band C-DOP model [Martin et al. 2016b].

The Doppler frequency shift $d f$ due to wind-waves is presented here as the equivalent surface velocity after projection from the LoS slant range to the surface and is called the wind-wave induced artifact surface velocity (WASV). The dependence of the WASV on incidence angle, wind speed and azimuth angle are presented in Figure 1-right for VV (blue) and HH (red) polarizations. The WASV is a large effect with magnitudes that can reach 0.5 to $2 \mathrm{~m} / \mathrm{s}$ depending on the wind speed (fig. 1 d), making it as large or larger than the contribution to Doppler shifts by most ocean surface currents. 
To first order, the WASV is most strongly determined by the wind direction with maximal amplitude observed in the upwind/downwind direction and WASV equal to zero crosswind (fig. 1 f f). In comparison, wind speed and incidence angle are second order effects on the magnitude of the WASV. The WASV decreases rapidly with increasing incidence angle (fig. 1-b). In the downwind direction, there are marked differences between the two polarizations at all incidence angle, and unlike NRCS, this difference occurs even at incidence angles within $25^{\circ}$ of nadir. Nevertheless, due to the projection of the surface current onto the radar slant range, the sensitivity of the total Doppler to the ocean surface current will be greater at larger incidence angles. For these reasons, Doppler frequency observations at higher incidence angles seem to be preferable.

\section{Method for the geophysical inversion}

\subsection{Overview}

The proposed geophysical inversion is based on a Bayesian approach, whereby a cost function is defined and subsequently minimized using leastsquare fitting to determine the wind and current vectors that are most consistent with radar observables (NRCS and Doppler shift in two squinted directions $90^{\circ}$ apart at one or more polarizations). In practice, as for scatterometry, with two independent backscatter views, there are in general four equally likely solutions Portabella 2002 leading to an ambiguity problem. An ambiguity selection procedure is then applied before assessing the retrieval performance. In practice, this method could not be used to resolve the ambiguity in an operational system, but the approach is well suited for a Monte-Carlo simulation and gives useful information on the capability of the different configurations to discriminate the ambiguous solutions.

\subsection{Cost function definition and setup}

The cost function $\left(J^{p p}\right)$ for the polarization $p p$ can be defined as the quadratic error between the observed and modeled estimates of NRCS $\left(\sigma_{i}^{0, p p}\right)$ in linear scale and the Doppler shift $\left(d f_{i}^{p p}\right)$ measured in each antenna look direction $(i)$ in polarization $p p$ for given wind and current vector 
Table 1: Experimental setup

Baseline instrument configuration

$30^{\circ}$ incidence angle

$\pm 45^{\circ}$ squint angle at the surface

$\mathrm{VV}$ and $\mathrm{HH}$ polarization (at the surface)

Gaussian noise on observables

$\overline{\Delta \sigma^{0}=k_{p} \times \sigma^{0}, \text { with } k_{p}=5 \%}$

$\Delta d f=5 \mathrm{~Hz}$

Geophysical Model Functions

KuMod based on NRCS GMF from NSCAT

KuDop based on Doppler frequency model from Envisat C-DOP scaled for Ku-band

Assumptions

No impact of wind/wave/current interactions and other local effects on NRCS and Doppler

conditions, as follows:

$$
\begin{aligned}
J_{p p}\left(\boldsymbol{u}_{\mathbf{1 0}}, \boldsymbol{c}\right) & =\frac{1}{2 N} \sum_{i=1}^{N}\left(\frac{\sigma_{\text {meas }, i}^{0, p p}-K u M o d\left(\boldsymbol{u}_{\mathbf{1 0}}-\boldsymbol{c}, p p\right)}{\Delta \sigma^{0}}\right)^{2} \\
& +\frac{1}{2 N} \sum_{i=1}^{N}\left(\frac{\left.d f_{\text {meas }, i}^{p p}-K u D o p\left(\boldsymbol{u}_{\mathbf{1 0}}-\boldsymbol{c}, p p\right)+2 . c_{/ / i} \cdot \sin \theta / \lambda_{e}\right)}{\Delta d f}\right)^{2}
\end{aligned}
$$

for a given instrument configuration (incidence angle, squint angle, noise). The cost function is unit-less and depends on the wind vector $\left(\boldsymbol{u}_{\mathbf{1 0}}\right)$ and the current vector $(\boldsymbol{c})$. It is therefore a function of 4 unknown variables. The parameters $\Delta \sigma^{0}=k_{p} \times \sigma^{0}$ and $\Delta d f$ are the values of the uncertainty assigned to $\sigma^{0}$ and $d f$ respectively. In this study, the baseline values for $k_{p}$ and $\Delta d f$ are $5 \%$ and $5 \mathrm{~Hz}$ respectively. $c_{/ / i}$ represents the surface current component in each antenna look direction $(i) . \lambda_{e}$ is the radar wavelength. $\mathrm{N}$ represents the number of antennas look-direction and is equal to 2 , except when the contributions are shown assuming a single antenna, then $N=1$. Both single polarization (i.e. VV-only, HH-only) and dual-polarization (VV and $\mathrm{HH}$ ) configurations have been considered. In the case of multiplepolarization inversion, the cost function is the average of the two single-pol cost functions. The overall experimental setup adopted in the study is summarized in Table 1 . 


\subsection{Monte-Carlo simulation framework to estimate retrieval performance}

In order to estimate the retrieval performance for wind and current vectors over a wide range of geophysical conditions, or for different instrument configuration, a Monte-Carlo approach is used based on the inversion framework established in section 3.1.

For each given geophysical condition (wind and current vectors) and instrumental configuration, the following steps are followed:

(a) The "true" NRCS $\left(\sigma^{0}\right)$ and Doppler shift $(d f)$ for the particular configuration is computed from the GMFs for each antenna look direction and polarization;

(b) A set of 2000 noisy observations are generated for each antenna look direction and polarization. Simulated observables are normally distributed, centered around the "true" observable with a standard deviation on $\sigma^{0}$ and $d f$ of $\Delta \sigma^{0}$ and $\Delta d f$ respectively;

(c) Local minima of the cost function $J$ defined in eq. (1) are found and give a set of ambiguous wind and current solutions;

(d) Ambiguities are selected using the algorithm described in the appendix;

(e) The results consist of 2000 simultaneously retrieved current and wind vectors from which the Root Mean Square Error (RMSE) is statistically derived.

\section{Results: Cost functions for typical setups}

The contributions of each cost function component are presented here for three typical setups. All setups have the same instrumental configuration: antennas looking at $45^{\circ}$ and $135^{\circ}$, incidence angle of $30^{\circ}$, noise of $5 \%, 5 \mathrm{~Hz}$, except that Setup 1 uses a single VV-polarization and Setup $2 \& 3$ use a dual $(\mathrm{VV}, \mathrm{HH})$ polarizations. A moderate surface current of $0.6 \mathrm{~m} / \mathrm{s}$ eastward is considered for the three setups. Setup $1 \& 2$ consider a wind speed of $8 \mathrm{~m} / \mathrm{s}$ eastward $\left(270^{\circ}\right)$ and Setup 3 a wind of $8 \mathrm{~m} / \mathrm{s}$ from $225^{\circ}$ (blowing parallel to one antenna look direction). The cost function is a function of 4 unknown variables (4D) and is presented on 2D wind field surface as slices for a particular current vector. 
In the following figures (Fig. 2, 3 and 4) showing the cost functions, white lines represent the antenna look directions and the white cross indicates the "true" wind vector. Low values of the cost function (dark blue) indicate the high likelihood value for the retrieved wind and current vectors. The apparently black areas, particularly pronounced in Fig. 2a, are linked to the black contour lines being close to each other, indicating the presence of strong gradients in the cost function. A cost function value of 1 , corresponds to the noise level.

\subsection{Setup 1: VV-polarization; wind eastward}

The contribution for Setup 1 of each cost function component is shown in Figure 2. The cost function is shown for a surface current slice of $\left(c_{u} ; c_{v}\right)$ $=(0.6 ; 0.0) \mathrm{m} / \mathrm{s}$ equal to the true current. On the left is shown the contribution assuming a single antenna configuration (represented as a white line). Figure 2 -a illustrates the contribution from the NRCS, single antenna, showing an elliptic shape minima, with good retrieval of the approximate value of the wind speed, but no information on the wind direction. Using both antennas but only NRCS (Fig. 2-b) leads to four solutions for the wind vectors, with good retrieved wind speed but ambiguities in wind direction as for the Seasat scatterometer Jones et al. 1982]. This directional ambiguity is partly alleviated with today's scatterometers, which use multiple $(>2)$ look directions to help resolve this directional ambiguity. Figure 2-c illustrates the contribution from the Doppler shift single antenna, showing a path of potential solutions perpendicular to the antenna look direction. Combination of both antennas with only Doppler shift enables the retrieval of a single wind vector (Fig. 2-d). With the noise figure assumed here, the cost function gradient is sharper when using NRCS only than with Doppler shift only, indicating a better ability to retrieve accurate wind vector with NRCS alone. Combining NRCS and Doppler shift with both look directions (Fig. 2f) gives single and sharp minimum that enables more accurate wind vector retrieval.

Figure 2 represented a slice for the current corresponding to the true current $\left(c_{u} ; c_{v}\right)=(0.6 ; 0.0) \mathrm{m} / \mathrm{s}$. Figure 3 shows how the cost function changes when the current slice is away from the truth. Each column of Figure 3 represents the same contribution as illustrated in Figure 2 -right but for different slices of surface current of (from left to right) $\left(c_{u} ; c_{v}\right)=$ $(0.0 ; 0.0) ;(1.0 ; 0.0) ;(3.0 ; 0.0) \mathrm{m} / \mathrm{s}$. Considering the contributions from the NRCS (Fig. 3-top), the shift in the slice of surface current from 0 to 3 $\mathrm{m} / \mathrm{s}$ impact linearly the minima position in the zonal wind direction as 

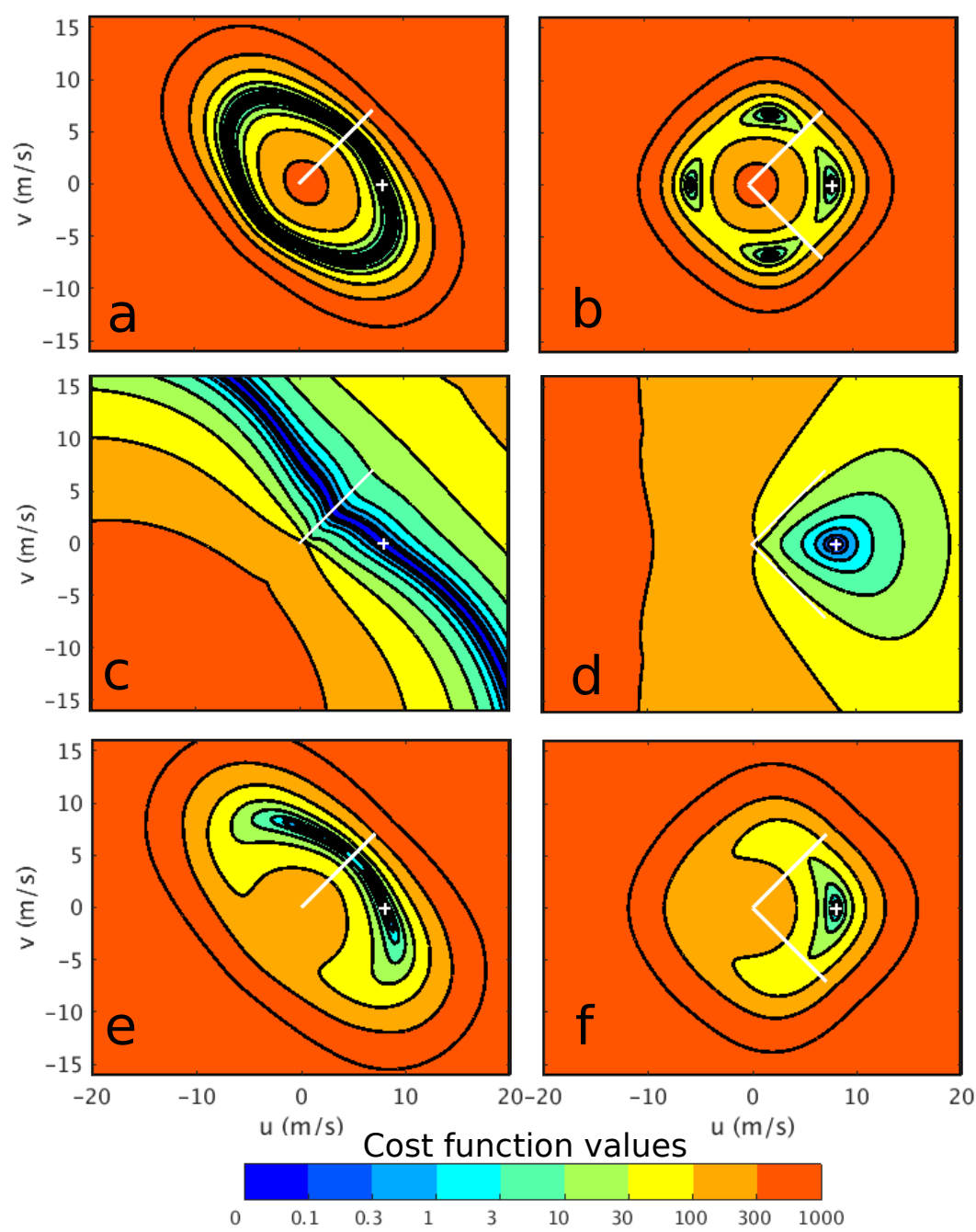

Figure 2: Illustration of the cost function components mapped in 2D wind vector space with respect to zonal $(\mathrm{u})$ and meridional $(\mathrm{v})$ wind for Setup 1. This shows the surface current slice of $\left(c_{u} ; c_{v}\right)=(0.6 ; 0) \mathrm{m} / \mathrm{s}$ equal the true current. Lower values of the cost function indicate the higher likelihood of the solution for the wind and current vector. The small white cross indicates the true wind vector $(8 \mathrm{~m} / \mathrm{s}$, eastward $)$ to be retrieved. White lines represent the antenna look directions. Incidence angle is $30^{\circ}$. Polarization is VV single-polarization. Different rows show the cost function based on (1st row) NRCS only; (2nd row) Doppler shift only; (3rd) NRCS + Doppler shift. Columns are for antenna look direction (left) in one direction only; (right) in two directions. 

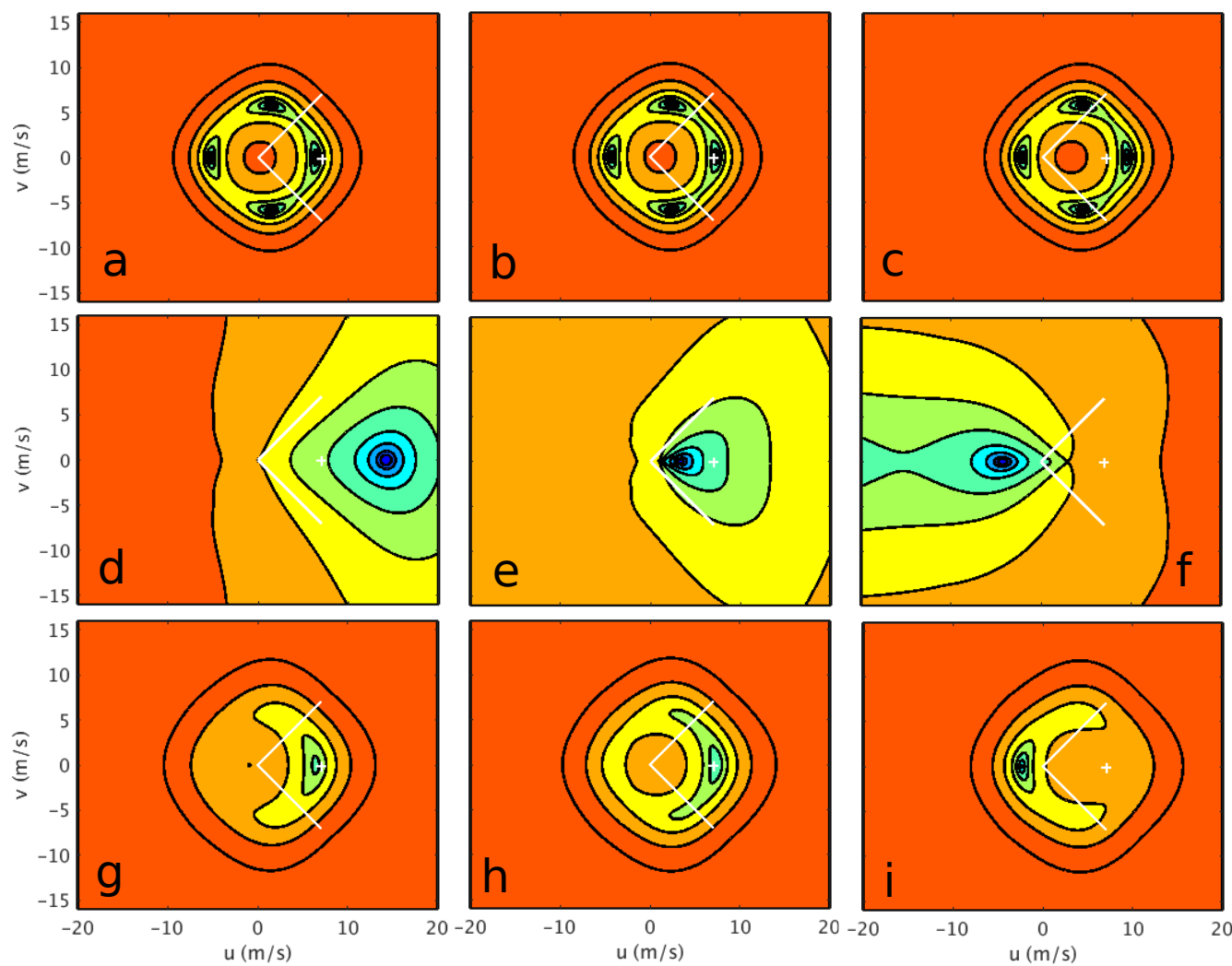

Figure 3: Same as Figure 2 right, showing the cost function components for Setup 1 but with different columns corresponding to different slices through surface current space. Examples shown correspond to $c_{v}=0 \mathrm{~m} / \mathrm{s}$ and $c_{u}$ (from left to right) $=0.0,1.0$ and 3.0 $\mathrm{m} / \mathrm{s}$. 
Table 2: Position of the minima in wind and current space (rounded at one decimal point) and value of the cost function $(\mathrm{J})$ for a noise of $5 \mathrm{~Hz}, 5 \%$ and a wind direction of $270^{\circ}$.

\begin{tabular}{|c|c|c|c|c|c|c|c|c|c|}
\hline & \multicolumn{9}{|c|}{ Setup 1: VV } \\
\hline & \multicolumn{4}{|c|}{ wind } & \multicolumn{4}{|c|}{ current } & \multirow[t]{2}{*}{$J$} \\
\hline & $\mathrm{u}$ & $\mathrm{V}$ & spd. & $\operatorname{dir} .\left(^{\circ}\right)$ & $c_{u}$ & $c_{v}$ & vel. & $\operatorname{dir} .\left(^{\circ}\right)$ & \\
\hline truth/min 0 & 8.0 & 0.0 & 8.0 & 270 & 0.6 & 0.0 & 0.6 & 90 & 0.00 \\
\hline $\min 1$ & -3.2 & 0.0 & 3.2 & 90 & 3.0 & 0.0 & 3.0 & 90 & 0.00 \\
\hline $\min 2$ & 3.1 & -5.6 & 6.4 & 330 & 1.6 & 1.1 & 2.0 & 56 & 0.00 \\
\hline $\min 3$ & 3.1 & 5.6 & 6.4 & 209 & 1.6 & -1.1 & 2.0 & 124 & 0.00 \\
\hline & \multicolumn{8}{|c|}{ Setup 2: VV+HH } & \\
\hline truth/min 0 & 8.0 & 0.0 & 8.0 & 270 & 0.6 & 0.0 & 0.6 & 90 & 0.00 \\
\hline $\min 1$ & -2.9 & 0.0 & 2.9 & 90 & 3.2 & 0.0 & 3.2 & 90 & 1.05 \\
\hline $\min 2$ & 3.4 & -5.5 & 6.5 & 328 & 1.7 & 1.2 & 2.1 & 54 & 0.63 \\
\hline $\min 3$ & 3.4 & 5.5 & 6.5 & 212 & 1.7 & -1.2 & 2.1 & 126 & 0.63 \\
\hline
\end{tabular}

expected. Indeed the current only impacts the relative wind to the moving ocean surface through the relation $\boldsymbol{u}_{\mathbf{1 0}}-\boldsymbol{c}$. With regard to the Doppler shift contribution to the cost function, the shift in current slice has a much stronger impact (Fig. 3-middle). The minimum position for the slice at $(0.0 ; 0.0) \mathrm{m} / \mathrm{s}$ (Fig. 3-d) in the wind space is close to $u=14 \mathrm{~m} / \mathrm{s}$ whereas it is close to $u=-5 \mathrm{~m} / \mathrm{s}$ for the slice at $(3.0 ; 0.0) \mathrm{m} / \mathrm{s}$ (Fig. 3-f), i.e. a factor $>6$ between the shift in the wind minimum and the shift in the slice of the surface current. This reveals the very strong interaction between the retrieval of the current and the wind and is due to the strong impact of the wind-induced WASV on the Doppler shift that is used to sense the surface current, as illustrated with the WASV GMF on Figure 1-d.

The lowest values of the full cost function (Fig. 2f f and Fig. 3-bottom) are obtained when the minima of the Doppler shift contribution coincide with one of the four minima of the NRCS contribution. This leads to four global solutions (Fig. 4-left), corresponding to four very different wind and current vector conditions. Similarly to Seasat, the four ambiguous solutions have similar relative wind speed [Wurtele et al. 1982]. The retrieved wind and current and cost function values of the 4 solutions for Setup 1 are given in Table 2. There is no distinction in the cost values between the truth and the three ambiguities for Setup 1 (single VV-polarization). With some $a$ priori knowledge of the magnitude of the current or wind direction, an operational system may however be able to identify which of the four solutions is 

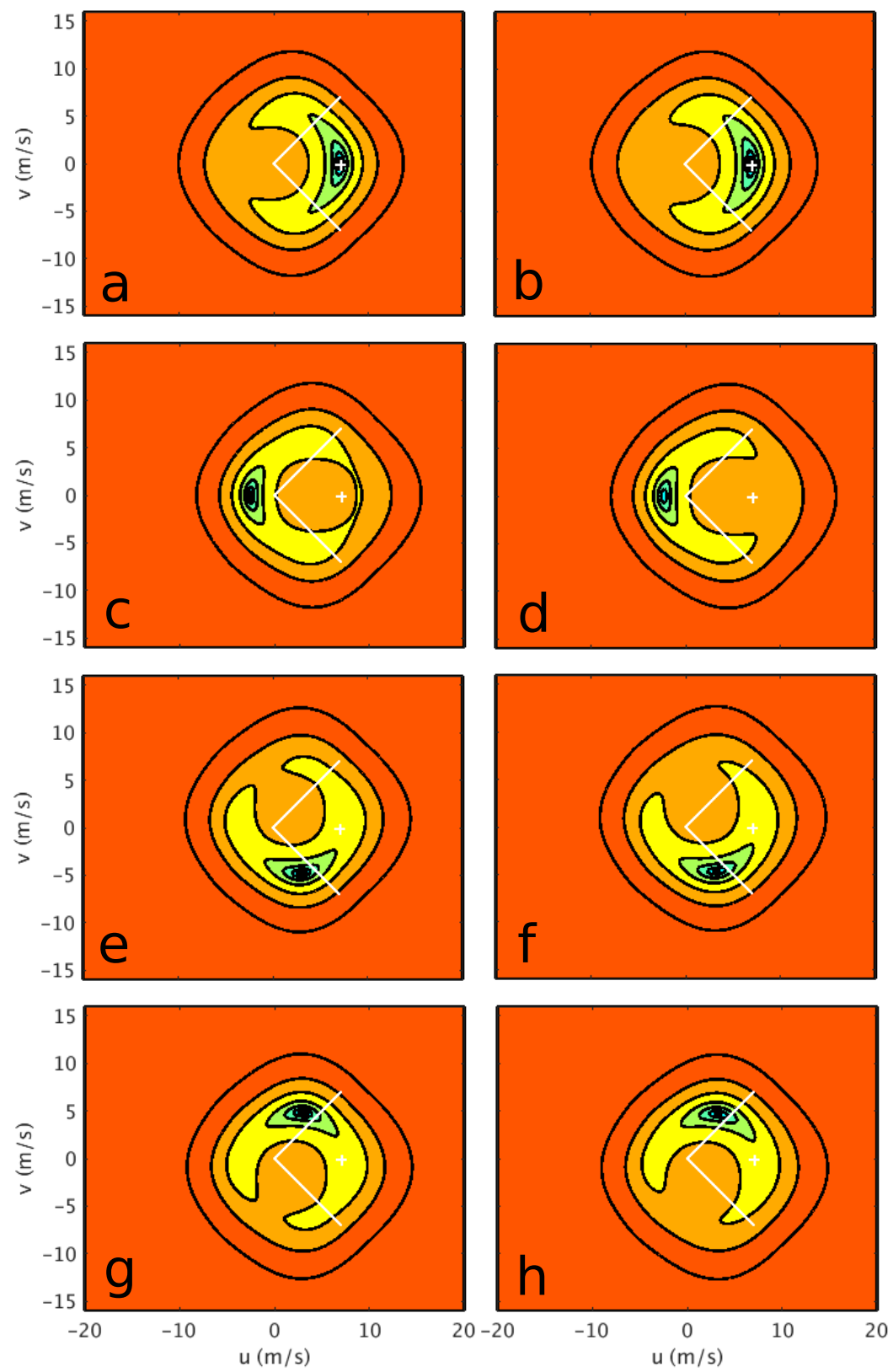

Figure 4: Same as Figure $2 \mathrm{f}$ but for the four values of surface current vector corresponding to the four local minima of the cost function using NRCS + Doppler shift in both antenna look direction. (left) Setup 1: single VV-polarization; (right) Setup 2: dual VV and HH polarizations. Current vector components $\left(c_{u} ; c_{v}\right)$ are from 'a' to ' $h$ ': $(0.6 ; 0.0)$, $(0.6 ; 0.0),(3.0 ; 0.0),(3.2 ; 0.0),(1.6 ; 1.1),(1.7 ; 1.2),(1.6 ;-1.1),(1.7 ;-1.2) \mathrm{m} / \mathrm{s}$. 
Table 3: Position of the minima in wind and current space (rounded at one decimal point) and value of the cost function $(\mathrm{J})$ for a noise of $5 \mathrm{~Hz}, 5 \%$ and a wind direction of $225^{\circ}$.

\begin{tabular}{|c|c|c|c|c|c|c|c|c|c|}
\hline & \multicolumn{9}{|c|}{ VV } \\
\hline & \multicolumn{4}{|c|}{ wind } & \multicolumn{4}{|c|}{ current } & \multirow[t]{2}{*}{$\mathrm{J}$} \\
\hline & $\mathrm{u}$ & $\mathrm{v}$ & spd. & $\operatorname{dir} .\left(^{\circ}\right)$ & $c_{u}$ & $c_{v}$ & vel. & $\operatorname{dir} .\left(^{\circ}\right)$ & \\
\hline truth $/ \min 0$ & 5.7 & 5.7 & 8.0 & 270 & 0.6 & 0.0 & 0.6 & 90 & 0.00 \\
\hline $\min 1$ & 6.9 & 4.3 & 8.2 & 238 & 0.3 & 0.3 & 0.4 & 47 & 0.00 \\
\hline $\min 2$ & -0.1 & -4.6 & 4.7 & 1 & 1.6 & 2.0 & 2.6 & 39 & 0.00 \\
\hline $\min 3$ & -3.5 & -1.6 & 3.8 & 65 & 2.4 & 1.3 & 2.7 & 62 & 0.00 \\
\hline & \multicolumn{8}{|c|}{ Setup 3: VV+HH } & \\
\hline truth $/ \min 0$ & 5.7 & 5.7 & 8.0 & 225 & 0.6 & 0.0 & 0.6 & 90 & 0.00 \\
\hline $\min 1$ & 6.9 & 4.4 & 8.1 & 237 & 0.3 & 0.3 & 0.4 & 43 & 0.04 \\
\hline $\min 2$ & 0.6 & -4.5 & 4.5 & 353 & 1.6 & 2.2 & 2.7 & 36 & 1.72 \\
\hline $\min 3$ & -3.3 & -1.0 & 3.5 & 74 & 2.6 & 1.3 & 2.9 & 64 & 1.66 \\
\hline
\end{tabular}

closest to the truth. Alternatively, one could use further information, such as observables with dual-polarizations as for Setup 2.

\subsection{Setup 2: VVEHHH polarizations; wind eastward}

The four solutions obtained by inversion for Setup 2 (dual polarization) are shown in fig. 4right and given in Table 2, The solutions for dual polarization appear very similar to those obtained for single VV-polarization, insofar as the inversion returns four solutions again. However, in contrast to the $\mathrm{VV}$ only case, there are differences between the values of the cost function of the four minima (Table 2), making it possible to identify the solution closest to the truth. The differences in the cost function are for a single observation below the noise level $(\mathrm{J}=1)$, but combinations of observations would enable to discriminate these ambiguities. There is also a slight difference in the retrieved vectors for the three ambiguities with, for example, a minimum for VV corresponding to an eastward current of 3.0 $\mathrm{m} / \mathrm{s}$ and of $3.2 \mathrm{~m} / \mathrm{s}$ for the dual polarizations case. This difference of values of the four minima confirms that, even at $30^{\circ}$ incidence, there is value in having dual polarization capability.

\subsection{Setup 3: VVEHH polarizations: wind blows parallel to one antenna}

When the wind is blowing parallel to one antenna look-direction as for Setup 3 (Figure 5 and Table 3 , wind direction of $225^{\circ}$ ), the four minima 

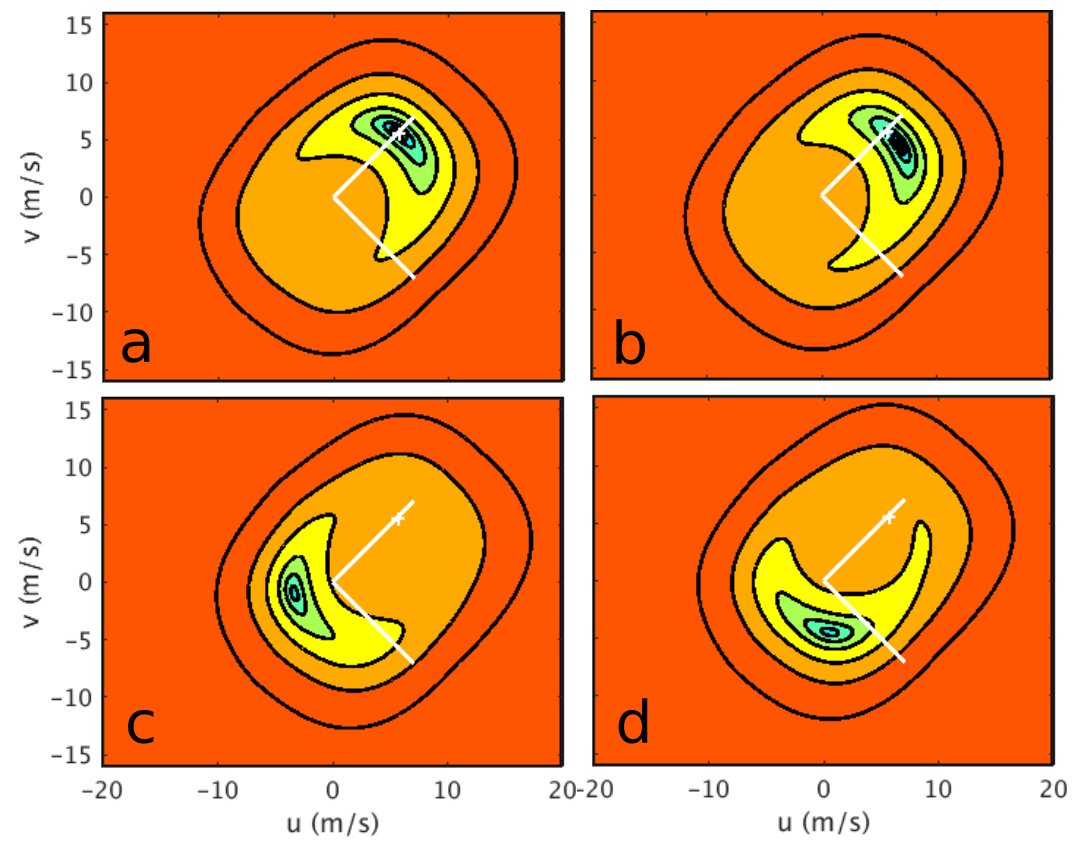

Figure 5: Same as Figure 4 but for Setup 3 with a true wind vector of $8 \mathrm{~m} / \mathrm{s}$ blowing from $225^{\circ}$. Examples shown are for dual $\mathrm{VV}+\mathrm{HH}$ polarizations and for current vector components $\left(c_{u} ; c_{v}\right)$ from 'a' to 'd': $(0.6 ; 0.0),(0.3 ; 0.3),(2.6 ; 1.3),(1.6 ; 2.2) \mathrm{m} / \mathrm{s}$. 
due to the NRCS tend to come together in pairs. The two solutions close to the truth have very similar cost values and similar wind speed and current velocity ( 8.1 vs $8.0 \mathrm{~m} / \mathrm{s}$ and 0.4 vs $0.6 \mathrm{~m} / \mathrm{s}$ ). Wind direction and more specifically current direction are significantly different between the two solutions $\left(237^{\circ}\right.$ vs $225^{\circ}$ and $43^{\circ}$ vs $\left.90^{\circ}\right)$. We have exactly the same behavior for a wind blowing in the same look direction as the other antenna (wind direction of $\left.315^{\circ}\right)$. For the two other wind directions parallel to either antenna look direction, i.e. $45^{\circ}$ and $135^{\circ}$, the two minima are even closer (not shown). The distinction between the two minima close to the truth for wind blowing parallel to one antenna look direction is hard to resolve even with dual polarization as both cost values are very low and the retrieved wind and current vectors are too close to be easily discriminated.

\section{Retrieval performance in different geophysical conditions}

Using a Monte-Carlo ensemble simulation approach, the inversion framework established in section 3.3 is now used to quantify the retrieval performance for wind and current vectors over a wide range of geophysical conditions.

The geophysical conditions considered in the Monte Carlo simulations covers wind speeds ranging between 3 and $20 \mathrm{~m} / \mathrm{s}$ and current velocities between 0 and $3 \mathrm{~m} / \mathrm{s}$, with all combinations of relative wind-current directions. The default instrument configuration is used, i.e. incidence angle of $30^{\circ}$, squint angle of $45^{\circ}$, dual polarization.

\subsection{Sensitivity of retrieval performance to wind}

Figure 6 top presents the retrieval performance for wind and current as a function of wind speed for a wind direction of $270^{\circ}$ (Fig. 6-a) and $225^{\circ}$ (Fig. 6-b). Retrieval performance is assessed by the Root Mean Square Error (RMSE).

For typical cases, when the wind is not blowing parallel to one of the antenna look directions, retrieval performance are similar to those presented in Figure 6-a. The error in current velocity shows only a very weak dependency with wind speed, and is typically below $0.1 \mathrm{~m} / \mathrm{s}$ whatever the noise figure, except at low wind speed for the highest noise figure $(12 \%, 5 \mathrm{~Hz})$. The retrieval error for current direction is slightly worse at low and high wind speed, linked to the larger error in wind direction at low winds and the larger error in wind speed at high winds. In all cases, except at low 

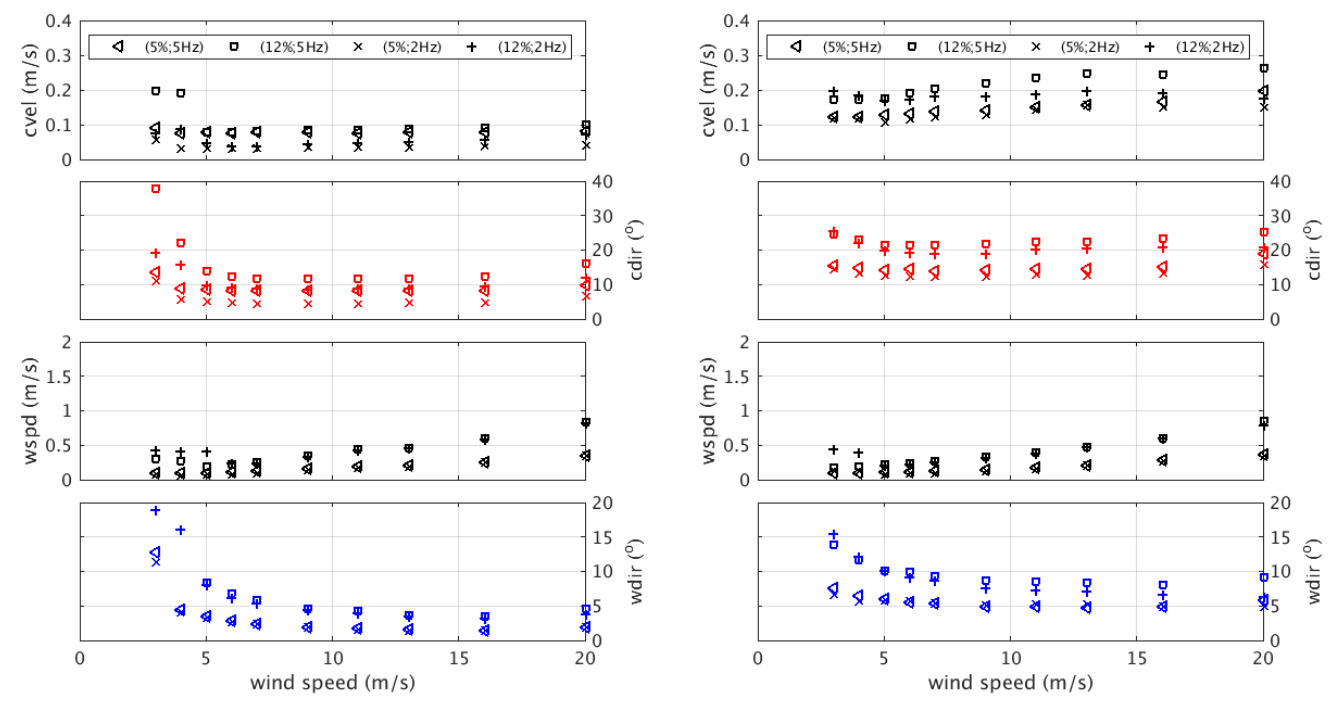

(a)

(b)

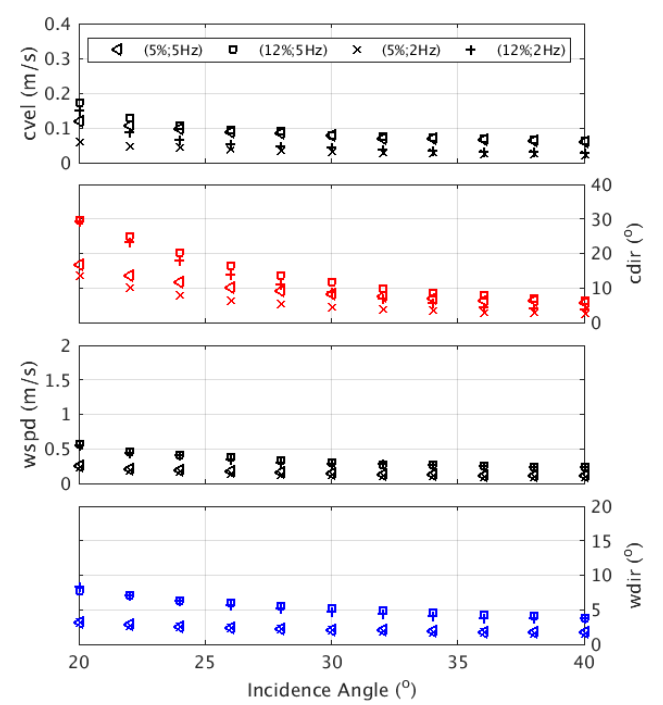

(c)

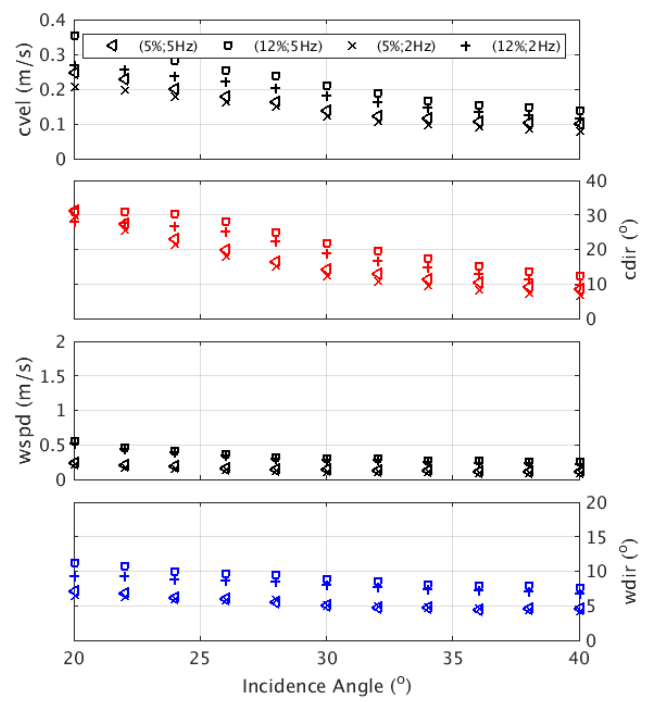

(d)

Figure 6: RMSE in $\mathrm{m} / \mathrm{s}$ for retrieved wind and current vectors as function of $(\mathrm{a}, \mathrm{b})$ wind speed for $30^{\circ}$ incidence (c, d) incidence angle for $8 \mathrm{~m} / \mathrm{s}$ wind speed. Wind direction is (a, c) $270^{\circ},(\mathrm{b}, \mathrm{d}) 225^{\circ}$. For each panel, the rows from top to bottom are the RMSE for the retrieved current velocity (black), current direction (red), wind speed (black) and wind direction (blue). Noise on Doppler shift is $2 \mathrm{~Hz}$ for the + and $\mathrm{x}$ symbols and $5 \mathrm{~Hz}$ for triangle and square markers. Noise on NR\&S radiometric resolution is $5 \%$ for triangle and cross markers, and $12 \%$ for square and plus symbols. Surface current is $0.6 \mathrm{~m} / \mathrm{s}$ at $270^{\circ}$. The inversion uses $\mathrm{VV}+\mathrm{HH}$ polarizations. 
wind for the highest noise on NRCS, the RMSE on current direction is below $15^{\circ}$. The retrieval performance for wind speed gets worse when wind speed increases, but the RMSE never exceeds $1 \mathrm{~m} / \mathrm{s}$ and is generally below $0.5 \mathrm{~m} / \mathrm{s}$. The RMSE on the wind direction is slightly worse in light wind conditions but above $4 \mathrm{~m} / \mathrm{s}$ remains always better than $10^{\circ}$ and is typically better than $5^{\circ}$. The wind retrieval performance (speed and direction) is only due to the noise on NRCS and does not depend on Doppler shift noise. Conversely, the retrieval performance for current depends on Doppler shift noise, but also on the wind retrieval performance, specifically that for wind direction. Wind direction has a very strong impact on the Doppler shift through WASV, hence on the retrieved current.

For cases when the wind is blowing parallel to one of the antenna look directions, as shown in Figure 6 b b, the retrieval performance is degraded for current velocity and direction as well as for wind direction, but the retrieval performance for wind speed is unchanged. Despite being degraded by about a factor two, the RMSE for wind direction stays below $10^{\circ}$ in most cases. As before, the performance for wind depends only on NRCS noise. The error on retrieved current stays below $0.2 \mathrm{~m} / \mathrm{s}$ excepted when noise on NRCS and Doppler shift is high, i.e. $(12 \% ; 5 \mathrm{~Hz})$. It also shows a small dependence on wind speed. RMSE on current direction remains better than $25^{\circ}$. Retrieval performance for current (velocity and direction) is largely dependent on the retrieval performance for wind direction and only weakly on Doppler shift noise.

\subsection{Sensitivity of retrieval performance to current}

The retrieval performance for wind speed and direction and current velocity is independent of the current velocity (not shown). As the retrieved current error is constant with current velocity $(0.1$ or $0.2 \mathrm{~m} / \mathrm{s}$ depending on wind direction with regard to antenna look-direction), the relative error increases with decreasing current. Similarly, the retrieval error on current direction is worse for low current velocity, linked to the stronger relative error between the estimated current vector and the truth. The current direction has not been found to have strong impact on any retrieved parameter.

\section{Retrieval performance for different instrument configurations}

In the previous section, we examined the sensitivity of the retrieval performance to geophysical conditions using the baseline instrument configura- 
tion, i.e. dual polarization (VV \&HH), $30^{\circ}$ incidence angle, $90^{\circ}$ separation in azimuth between the two antennas look directions.

In this section, different instrument configurations are examined to assess their effect on the retrieval performance. The geophysical conditions are fixed and correspond to the two cases (Setup 2 and 3) presented in section 4 i.e. an eastward current of $0.6 \mathrm{~m} / \mathrm{s}$ and a wind of $8 \mathrm{~m} / \mathrm{s}$ at respectively $270^{\circ}$ (Setup 2, best case scenario) and $225^{\circ}$ (Setup 3, worst case scenario).

First, the retrieval performance for the current and wind vectors has been tested with different polarization options: $\mathrm{VV}+\mathrm{HH}$, VV-only and $\mathrm{HH}-$ only. Tests have been conducted with different current velocity: 0.6, 1.0, 1.5 $\mathrm{m} / \mathrm{s}$. For all cases, the HH-only configuration performs considerably worse than other polarization options, as the backscattered signal is lower than in VV-polarization. This configuration can therefore be readily discarded. When the current is not strong $(<0.6 \mathrm{~m} / \mathrm{s})$, the RMSE of the current and wind vectors are very similar for $\mathrm{VV} \& \mathrm{HH}$ and VV-only, if only the ambiguity closest to current values of $0 \mathrm{~m} / \mathrm{s}$ is considered. For stronger current, knowledge of e.g. current magnitude or wind direction is needed in order to resolve the ambiguities experienced with VV-only, otherwise the performance become unacceptable (due to the ambiguities). In contrast, using the ambiguity selection algorithm proposed in section 3.3, the dual-polarization (VV\&HH) configuration is able to resolve the ambiguities and leads to constant performance whatever the current velocity as in the previous section.

Considering the choice of squint angles, changing the $90^{\circ}$ separation in azimuth between the two antennas look direction degrades the isotropic performance for the current retrieval without any other positive benefits and is therefore not discussed further.

There is significant improvement in performance with increasing incidence angles (Figure 6-bottom), particularly for current and, to a lesser extent, wind. The wind retrieval is very good at all incidence angles, always better than $0.5 \mathrm{~m} / \mathrm{s}$ and $\sim 10^{\circ}$ for wind speed and direction respectively (here for a wind speed of $8 \mathrm{~m} / \mathrm{s}$ ). For a favorable case (Setup 2, Figure 6-c) when the wind is not blowing parallel to an antenna's look direction, the reduction in current vector retrieval error is particularly dramatic between 20 and $25^{\circ}$ incidence angles, with further smaller improvement up to $30^{\circ}$, but no further improvements for higher incidence angles. This is particularly true when the noise is important for the Doppler shift and/or NRCS. Indeed, with increasing incidence angle, wind modulation in azimuth becomes stronger, making the wind retrieval easier particularly for high noise 
value (12\%) on NRCS [Wentz \& Smith 1999; Quilfen et al. 1999, Quilfen \& Chapron 2015]. Together with the lower WASV magnitude and stronger sensitivity to current due to the projection on the surface at higher incidence angle, this explains the better performance for retrieved current when using incidences away from nadir.

For less favorable cases when the wind is blowing parallel to one of the antenna look directions (Setup 3, Figure 6-d), the current vector retrieval error shows important reduction with increasing incidence angle up to $40^{\circ}$ without any noticeable threshold. For this configuration, wind blowing parallel to one of the antenna look directions, the sensitivity to wind direction is weaker and does not improve significantly with incidence angle [Stoffelen \& Portabella 2006]. There is, as explained previously, a stronger sensitivity to currents at high incidence angles due to the projection on the slant range, but the main improvement is due to the lower amplitude of the WASV at higher incidence angles (Fig. 1-right).

\section{Discussion and Limitations}

This study highlights the ability to retrieve current and wind better than $0.1 \mathrm{~m} / \mathrm{s} ; 10^{\circ}$ for current and $0.5 \mathrm{~m} / \mathrm{s} ; 5^{\circ}$ for wind for typical wind and current conditions. When wind direction is aligned with one of the antenna line-of-sight directions, the performance is degraded but remains typically better than $0.2 \mathrm{~m} / \mathrm{s}$ and $25^{\circ}$ for retrieved current and $0.5 \mathrm{~m} / \mathrm{s}$ and $15^{\circ}$ for wind. This degraded current vector retrieval is linked to the degraded performance for the retrieved wind direction. The WASV magnitude could be higher than $1 \mathrm{~m} / \mathrm{s}$ ( $30^{\circ}$ incidence) and is to first order a function of wind direction. The origin of this degraded retrieval for wind direction is discussed next.

Figure 7 represents the NRCS sensitivity to wind direction, following Stoffelen \& Portabella 2006]. The total sensitivity to wind direction has four local minima. These minima correspond to the directions parallel to the antennas look directions and explain directly the degraded performance for retrieved wind direction. The results presented here were obtained with a relative simple inversion scheme that made no attempt to optimize the inversion by weighing different effects. It is thought that some improvements could be achieved with a more advanced inversion scheme such as those developed in scatterometry, but this would not resolve the absence of NRCS sensitivity to wind direction in these four directions. The addition of a 


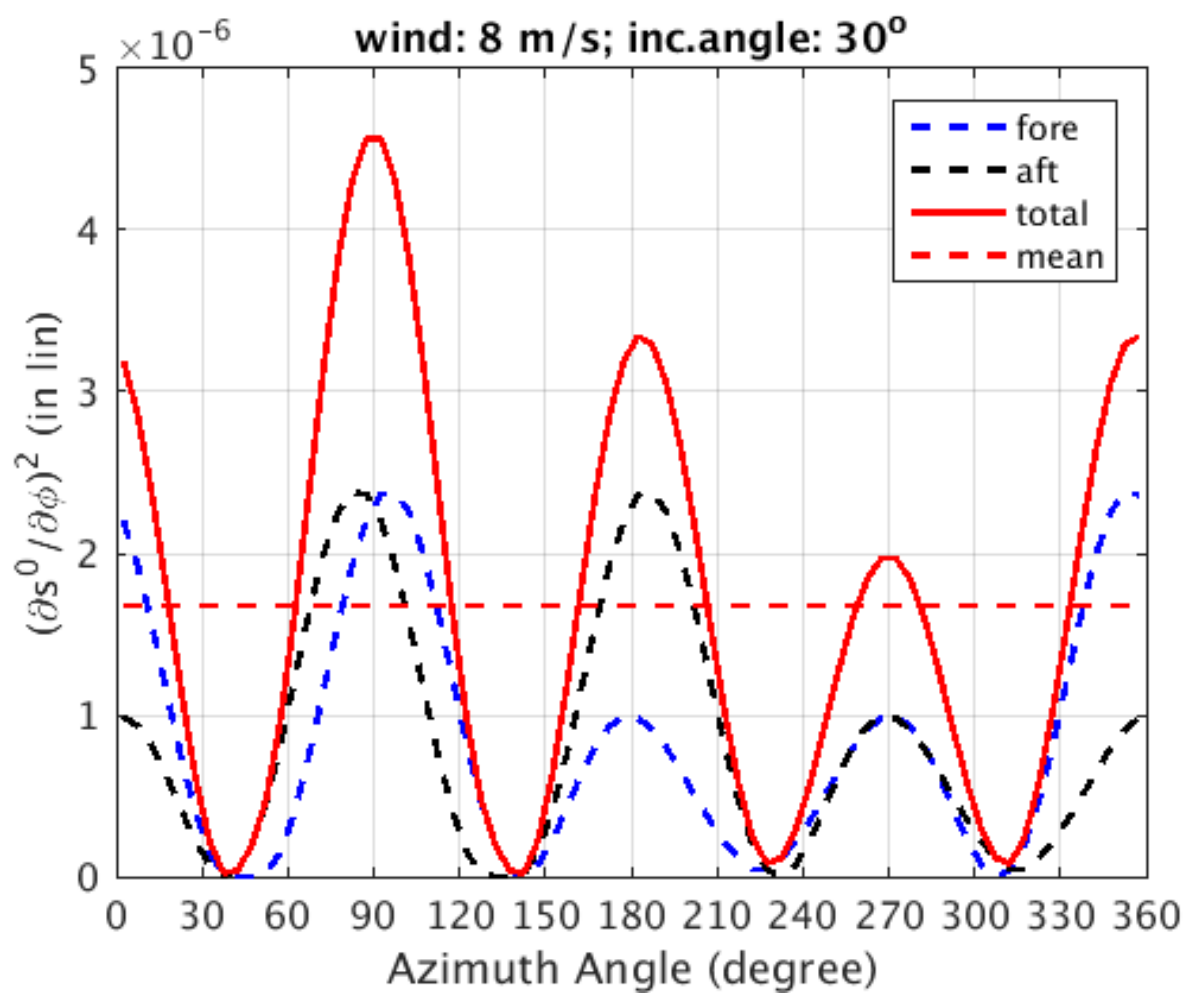

Figure 7: NRCS sensitivity to wind direction $\left(d \sigma^{0} / d \varphi\right.$, with $\varphi$ the wind direction) as a function of wind direction relative to the satellite heading north for a $8 \mathrm{~m} / \mathrm{s}$ wind speed and $30^{\circ}$ incidence angle. Antennas are oriented towards $45^{\circ}$ (fore) and $135^{\circ}$ (aft). Dashed blue (respectively black) lines are the NRCS sensitivity using only the fore (resp. aft) antenna looking direction. The red line represents the sum of the two and corresponds to the total NRCS sensitivity to wind direction. The dashed red line represents the mean total sensitivity over all wind directions. 
third broadside-look direction, as for ASCAT, is thought to be the optimal geometry to retrieve correctly the wind direction and is under study.

Results have been obtained with two levels of noise for the radiometric resolution $\left(k_{p}=5 \% ; 12 \%\right)$ and for Doppler shift $(2$ and $5 \mathrm{~Hz})$. These choices of noise levels are discussed next. Envisat-ASAR for a spatial resolution of $8 \mathrm{~km}$ had a radiometric resolution $k_{p}$ better than $8 \%$ [Torres et al. [2012] and a Doppler noise level better than (Ku-band equivalent) $12 \mathrm{~Hz}$ [Hansen et al. 2011. ESA Sentinel-1 achieves for a spatial resolution of $1 \mathrm{~km}$ a radiometric resolution $k_{p}$ better than 10,4 , and $2 \%$ respectively for the Extra Wide swath (EW), Interferometric Wide swath (IW), and StripMap (SM) mode (wind speed $>3 \mathrm{~m} / \mathrm{s}$ ) Torres et al. 2012]. However an equivalent noise on Doppler shift of $5 \mathrm{~Hz}$ in $\mathrm{Ku}$-band is achieved only for spatial resolutions of 5, 3, or $1.5 \mathrm{~km}$ respectively for Sentinel-1 EW, IW and SM modes (H. Johnsen, OSCM Brest 2015). The ESA Ocean Surface Current Mission (OSCM) study conducted by Airbus D \&S UK for a $4 \mathrm{~km}$ spatial resolution provides figures for radiometric resolution $k_{p}<4.5 \%$ (wind speed $>3 \mathrm{~m} / \mathrm{s}$ ) and for Doppler noise better than $d f=2 H z$ Airbus Defence \& Space 2015. To summarize, the lowest noise figure $(5 \% ; 2 \mathrm{~Hz})$ used in this study is consistent with a spatial resolution of $4 \mathrm{~km}$ (OSCM study). A noise figure of $(5 \% ; 5 \mathrm{~Hz})$ is consistent with Sentinel-1 SM, IW and EW modes for spatial resolutions of $1.5,3$, or $5 \mathrm{~km}$.

In this study only the instrumental noise, quantified by the radiometric resolution and the Doppler noise, has been taken into account. Another important source of noise is the so-called geophysical noise that comes from the wind sub-cell variability and from GMF errors. Mejia et al. [1999] and Rivas et al. 2009] proposed estimates of noise introduced by geophysical variability, combining sub-cell wind variability and GMF errors. The empirically derived model based on QuikSCAT [Rivas et al. 2009] gives $k_{\text {geo }}=0.05+2.2 \times e^{-u_{10} / 2}$ for a spatial resolution of $50 \mathrm{~km}$, equivalent to $12 \%(54 \%)$ at $7 \mathrm{~m} / \mathrm{s}(3 \mathrm{~m} / \mathrm{s})$ wind speed. The [Mejia et al. 1999] estimates using NSCAT and ECMWF are much larger with e.g. $k_{\text {geo }} \sim 80 \%$ at $6 \mathrm{~m} / \mathrm{s}$ wind speed, $36^{\circ}$ incidence angle. The strong values empirically derived in the latter study are certainly impacted by errors from the numerical weather prediction (ECMWF) winds used in the 90s and from the low effective resolution of the model compared to the observations and are therefore difficult to consider for use in our study. The GMFs used in this study have been developed at coarse resolution (tens of $\mathrm{km}$ ) and might not be optimal at higher resolution. However many studies point out the good quality of the 
wind retrieval at high resolution using a coarse resolution backscatter GMF, e.g. [Zhang et al. 2012; Jacobsen et al. 2015; Mouche \& Chapron 2015; Ahsbahs et al. [2017]. Concerning the impact of local wind variability, de Kloe 2003 propose the following geophysical noise $\left(k_{g e o}\right)$ relation to the spatial resolution $r$ (in $\mathrm{km}$ ) for wind speed $u_{10}$ (in $\mathrm{m} / \mathrm{s}$ ) below $16 \mathrm{~m} / \mathrm{s}$ :

$$
k_{\text {geo }}=0.644 \times 10^{-3} \times\left(\frac{r}{50}\right)^{\frac{1}{3}} \times\left(u_{10}-16.0\right)^{2}
$$

For $7 \mathrm{~m} / \mathrm{s}$ wind speed and $50 \mathrm{~km}$ resolution, the geophysical noise is $5 \%$ and decreases to $2 \%$ and $1 \%$ for spatial resolution of $4 \mathrm{~km}$ and $1 \mathrm{~km}$. At $3 \mathrm{~m} / \mathrm{s}$, it stays below $5 \%(3 \%)$ at $4 \mathrm{~km}(1 \mathrm{~km})$ resolution. The GMF errors could arise from unconsidered or complex geophysical conditions such as rain, sea surface temperature or sea state. In particular, GMF errors could potentially be non-negligible in presence of strong local wave breaking, for example, due to wind/wave/current interactions. In these cases, the GMFs used here might not be sufficiently accurate. Kudryavtsev et al. 2014] highlight interactions that occur on fine filaments narrower than $1 \mathrm{~km}$ affecting backscatter. For the Doppler signature, airborne measurements over a strong and narrow coastal jet suggest that wind/wave/current interactions have little impact on the WASV GMF [Martin \& Gommenginger 2017]. To conclude, for the expected high-resolution (1-4 km) of the proposed system, the geophysical noise originated from the local wind variability is foreseen to be small and the GMF errors will probably dominate initially, but should improve as more data are harvested. The study has been conducted for two radiometric resolution values $\left(k_{p}=5 \%\right.$ and $\left.12 \%\right)$ and led to similar conclusions. Whereas the low value $\left(k_{p}=5 \%\right)$ might be too small to account for both instrumental and geophysical noise, particularly at low wind speed, the high value $\left(k_{p}=12 \%\right)$ might be sufficient for most cases.

Results presented in this paper indicate that a VV-only configuration could be adequate in regions where ocean surface currents are weak or where reliable a priori information about the current magnitude is available (e.g. from a numerical model). More generally though, when currents are strong or there is no knowledge of the likely magnitude of the currents, these results suggest that a dual polarization VV \& HH presents better skill to unfold the ambiguities. The benefit of having HH-polarization in addition to $\mathrm{VV}$ is found to be useful at all incidence angle when considering the Doppler shift, and at incidence angle higher than $25^{\circ}$ for NRCS. Moreover, some studies (e.g., Kudryavtsev et al. [2014]; Mouche \& Chapron [2015]) have shown that dual co-polarization helps to detect and quantitatively discriminate ocean 
surface roughness signatures as the local distribution of breaking waves changes due to surface current gradients, or Bragg waves change due to the effects of an atmospheric front.

\section{Conclusions and Recommendations}

This numerical simulation study has described and tested an inversion strategy for the simultaneous retrieval of current and wind vectors for a dual-beam squinted interferometric SAR system, and quantified the expected retrieval performance in different geophysical conditions and instrumental configurations. Simultaneous current and wind vectors are retrieved with scientifically useful accuracy and precision for realistic instrument noise values $\left(k_{p}=5 \%\right.$ or $12 \%$, Doppler noise of 2 or $5 \mathrm{~Hz}$ ). Typical root-meansquare errors (RMSE) are better than $0.1 \mathrm{~m} / \mathrm{s}$ and $10^{\circ}$ for currents and better than $0.5 \mathrm{~m} / \mathrm{s}$ and $5^{\circ}$ for winds. Larger errors are observed when the wind direction is aligned with one antenna's line-of-sight (LoS) direction (up or downwind) but stay typically below $0.2 \mathrm{~m} / \mathrm{s}$ and $25^{\circ}$ for currents and $15^{\circ}$ for wind direction (wind speed retrieval is not affected).

The retrieval performance has been tested over a wide range of geophysical conditions (wind and current) and the wind direction has been found to have the most significant impact. Other impacts were found, such as the degraded performance for current retrieval at low wind speed $(<5 \mathrm{~m} / \mathrm{s})$ when the backscattered signal is weak. At low current velocity, the performance for retrieved current direction is degraded as there is a larger relative error between the estimated current vector and the truth. The current direction has no significant impact on any retrieved parameter.

This study highlights that there are four ambiguous solutions for the geophysical inversion of wind and current vectors. The four ambiguous solutions typically lie within an equivalent current range of $\sim 1 \mathrm{~m} / \mathrm{s}$ of each other and a wind direction of tens of degrees. Similarly to Seasat, the four ambiguous solutions have similar relative wind speed. In the case where the wind is aligned with one of the antenna's LoS, ambiguities tend to merge in pairs. This partly explains the greater retrieval uncertainty for these conditions. Dual polarization $(\mathrm{VV}+\mathrm{HH})$ helps to discriminate these ambiguities and might be required in areas where prior information on the current and wind are not reliable, such as in highly dynamic area like the coastal zone.

To achieve RMSE better than $0.1 \mathrm{~m} / \mathrm{s}$ and $10^{\circ}$ for retrieved currents whatever the wind direction, it is necessary to improve the sensitivity of 
the system to the wind direction when the wind is aligned with one of the antenna's LoS. Error in wind direction strongly affects the retrieved current through the wind-wave induced artifact surface velocity (WASV), which is at first order a function of wind direction. Increasing the incidence angle $\left(>35^{\circ}\right)$ increases the sensitivity to current vector due to the projection geometry and to the reduced WASV magnitude. An improvement to the sensitivity to wind direction could be achieved with lower noise on NRCS $\left(k_{p} \leq 5 \%\right)$ and/or higher incidence angle $\left(>35^{\circ}\right)$, but more certainly with the addition of a third look direction in the across-track direction, a configuration similar to ASCAT. This option is currently being evaluated and has been proposed for the SEASTAR concept submitted to the ESA call for Earth Explorer 10 (EE10) missions ideas.

\section{Acknowledgment}

The present work has been based in part on results from the WaPA study funded by an European Space Agency contract AO/1-7051/12/NL/AF 'Coastal and Ocean Surface Currents Mission Study: Wavemill Product Assessment (WaPA)' but has been mainly supported by the UK Centre for Earth Observation Instrumentation and Space Technology (CEOI-ST) Call for Mission and Technology Preparation Activities for ESA Earth Explorer 9 'Developing a successful Ocean Surface Current Mission proposal for ESA Earth Explorer 9' and the 10th Call 'SEASTAR+: enhancing the mission concept' awards.

The authors would like to thank Sam Doody, José Marquez (Airbus Defence \& Space Ltd, UK), Ad Stoffelen (KNMI) and Meric Srokosz (NOC) for their helpful comments while discussing the results. 


\section{References}

Ahsbahs, T., Badger, M., Karagali, I., \& Larsén, X. G. (2017). Validation of Sentinel-1A SAR coastal wind speeds against scanning LiDAR. Remote Sensing, 9. doi 10.3390/ rs9060552.

Airbus Defence \& Space (2015). OSCM Instrument Design \& Performance Analysis: D8. Technical Report ESA/ESTEC - OSCM-ASU-TN.008.

Buck, C. (2005). An extension to the wide swath ocean altimeter concept. In Geoscience and Remote Sensing Symposium, 2005. IGARSS '05. Proceedings. 2005 IEEE International (pp. 5436-5439). volume 8. doi:10.1109/IGARSS.2005.1525970.

Chapron, B., Collard, F., \& Ardhuin, F. (2005). Direct measurements of ocean surface velocity from space: Interpretation and validation. Journal of Geophysical Research: Oceans, 110. URL: http://dx.doi.org/10.1029/2004JC002809. doi:10. 1029/2004JC002809.

Fois, F., Hoogeboom, P., Le Chevalier, F., \& Stoffelen, A. (2015). An analytical model for the description of the full polarimetric sea surface Doppler signature. Journal of Geophysical Research: Oceans, (pp. n/a-n/a). URL: http://dx.doi.org/10.1002/ 2014JC010589, doi:10.1002/2014JC010589.

Graber, H. C., Thompson, D. R., \& Carande, R. E. (1996). Ocean surface features and currents measured with synthetic aperture radar interferometry and HF radar. Journal of Geophysical Research: Oceans, 101, 25813-25832. URL: http://dx.doi. org/10.1029/96JC02241, doi:10.1029/96JC02241.

Hansen, M., Collard, F., Dagestad, K., Johannessen, J., Fabry, P., \& Chapron, B. (2011). Retrieval of Sea Surface Range Velocities From Envisat ASAR Doppler Centroid Measurements. Geoscience and Remote Sensing, IEEE Transactions on, 49, 3582-3592. doi $10.1109 /$ TGRS . 2011.2153864.

Jacobsen, S., Lehner, S., Hieronimus, J., Schneemann, J., \& Kühn, M. (2015). Joint offshore wind field monitoring with spaceborne SAR and platform-based Doppler LIDAR measurements. ISPRS - International Archives of the Photogrammetry, Remote Sensing and Spatial Information Sciences, XL-7/W3, 959966. URL: http://www . int-arch-photogramm-remote-sens-spatial-inf-sci. net/XL-7-W3/959/2015/, doi:10.5194/isprsarchives-XL-7-W3-959-2015

Jones, W. L., Schroeder, L. C., Boggs, D. H., Bracalente, E. M., Brown, R. A., Dome, G. J., Pierson, W. J., \& Wentz, F. J. (1982). The SEASAT-A satellite scatterometer: The geophysical evaluation of remotely sensed wind vectors over the ocean. Journal of Geophysical Research: Oceans, 87, 3297-3317. URL: http://dx.doi.org/10.1029/ JC087iC05p03297, doi $10.1029 / J C 087 i C 05 p 03297$

de Kloe, J. (2003). Optimisation of rotating, range-gated, fanbeam scatterometer for wind retrieval, task 2 a report, GMF and wind field definition, and wind retrieval. Technical Report ESA/ESTEC Contract No. 14383/00/NL/DC, KNMI.

Kudryavtsev, V., Kozlov, I., Chapron, B., \& Johannessen, J. A. (2014). Quadpolarization SAR features of ocean currents. Journal of Geophysical Research: Oceans, (pp. n/a-n/a). URL: http://dx.doi.org/10.1002/2014JC010173. doi:10. 1002/2014JC010173.

Lapeyre, G., \& Klein, P. (2006). Impact of the small-scale elongated filaments on the oceanic vertical pump. Journal of Marine Research, 64, 835- 
851. URL: http://www.ingentaconnect.com/content/jmr/jmr/2006/00000064/ 00000006/art00004 doi:doi:10.1357/002224006779698369.

Lévy, M., Klein, P., Tréguier, A. M., Iovino, D., Madec, G., Masson, S., \& Takahashi, K. (2010). Modifications of gyre circulation by sub-mesoscale physics. Ocean Modelling, 34, 1-15. URL: http://www.sciencedirect.com/science/article/pii/ S1463500310000582, doi http://dx.doi.org/10.1016/j.ocemod.2010.04.001.

Martin, A., Gommenginger, C., \& Srokosz, M. (2016a). Developing a succesful ocean surface current mission proposal for ESA Earth Explorer 9. WP2: Increasing Scientific Readiness Level. Technical Report CEOI-ST Call for Mission and Technology Preparation Activities CEOI-ST Call for Mission and Technology Preparation Activities for ESA Earth Explorer 9.

Martin, A. C. H., \& Gommenginger, C. (2017). Towards wide-swath high-resolution mapping of total ocean surface current vectors from space: Airborne proof-of-concept and validation. Remote Sensing of Environment, 197, 58-71. URL: http://www.sciencedirect.com/science/article/pii/ S0034425717302195, doi https://doi.org/10.1016/j.rse.2017.05.020.

Martin, A. C. H., Gommenginger, C., Marquez, J., Doody, S., Navarro, V., \& Buck, C. (2016b). Wind-Wave induced velocity in ATI SAR Ocean Surface Currents: First experimental evidence from an airborne campaign. Journal of Geophysical Research: Oceans, . doi:10.1002/2015JC011459.

Martin, A. P., \& Richards, K. J. (2001). Mechanisms for vertical nutrient transport within a north atlantic mesoscale eddy. Deep Sea Research Part II: Topical Studies in Oceanography, 48, 757 - 773. URL: http:// wWw.sciencedirect.com/science/article/pii/S0967064500000965. doi/http:// dx.doi.org/10.1016/S0967-0645(00)00096-5.

Mejia, C., Badran, F., Bentamy, A., Crepon, M., Thiria, S., \& Tran, N. (1999). Determination of the geophysical model function of NSCAT and its corresponding variance by the use of neural networks. Journal of Geophysical Research: Oceans, 104, 11539-11556. URL: http://dx.doi.org/10.1029/1998JC900118, doi:10.1029/ 1998 JC900118.

Monaldo, F. M., Jackson, C. R., \& Pichel, W. G. (2013). Seasat to RADARSAT-2: Research to operations. Oceanography, 26, 34-45.

Mouche, A., \& Chapron, B. (2015). Global C-Band Envisat, RADARSAT-2 and Sentinel-1 SAR measurements in copolarization and cross-polarization. Journal of Geophysical Research: Oceans, 120, 7195-7207. URL: http://dx.doi.org/10.1002/ 2015JC011149, doi:10.1002/2015JC011149.

Mouche, A., Collard, F., Chapron, B., Dagestad, K., Guitton, G., Johannessen, J., Kerbaol, V., \& Hansen, M. (2012). On the Use of Doppler Shift for Sea Surface Wind Retrieval From SAR. Geoscience and Remote Sensing, IEEE Transactions on, 50. doi 10.1109/TGRS.2011.2174998.

Portabella, M. (2002). Wind Field Retrieval from Satellite Radar Systems. Ph.D. thesis Universitat de Barcelona. Departament d'Astronomia i Meteorologia. URL: http: //hdl.handle.net/10803/734.

Portabella, M., \& Stoffelen, A. (2004). A probabilistic approach for seawinds data assimilation. Quarterly Journal of the Royal Meteorological Society, 130, 127-152. URL: http://dx.doi.org/10.1256/qj.02.205 doi:10.1256/qj.02.205 
Quilfen, Y., \& Chapron, B. (2015). Impacts of ocean wind on Wavemill measurements. Tech . Report for ESA "Coastal and Open Ocean Surface Currents Mission Study: Wavemill Product Assessment - WaPA". WaPA/WP3000 ESA/ESTEC Contract No. 4000107347/NL/AF.

Quilfen, Y., Chapron, B., Bentamy, A., Gourrion, J., Elfouhaily, T., \& Vandemark, D. (1999). Global ERS 1 and 2 and NSCAT observations: Upwind/crosswind and upwind/downwind measurements. Journal of Geophysical Research: Oceans, 104, 11459-11469. URL: https://doi.org/10.1029/1998jc900113. doi:10.1029/ 1998 jc900113.

Quilfen, Y., Chapron, B., Collard, F., \& Vandemark, D. (2004). Relationship between ERS scatterometer measurement and integrated wind and wave parameters. Journal of Atmospheric and Oceanic Technology, 21, 368-373. URL: http:// dx.doi.org/10.1175/1520-0426(2004)021<0368:RBESMA>2.0.C0;2 doi:10.1175/ 1520-0426 (2004) 021<0368:RBESMA $>2.0 . \mathrm{CO} ; 2$.

Quilfen, Y., Chapron, B., \& Vandemark, D. (2001). The ERS scatterometer wind measurement accuracy: Evidence of seasonal and regional biases. Journal of Atmospheric and Oceanic Technology, 18, 1684-1697. URL: https://doi.org/10.1175/1520-0426(2001) 018<1684: TESWMA $>2.0 . C 0 ; 2$ doi $10.1175 / 1520-0426(2001) 018<1684:$ TESWMA $>2.0$. CO ; 2 . arXiv:https://doi.org/10.1175/1520-0426(2001)018<1684:TESWMA>2.0.C0;2.

Rivas, M. B., de Kloe, J., \& Stoffelen, A. (2009). Study of an Objective Performance Measure for Spaceborne Wind Sensors: Final report. Technical Report ESA/ESTEC Contract No. 18041/04/NL/AR.

Romeiser, R., Runge, H., Suchandt, S., Kahle, R., Rossi, C., \& Bell, P. (2014). Quality assessment of surface current fields from TerraSAR-X and TanDEM-X along-track interferometry and doppler centroid analysis. Geoscience and Remote Sensing, IEEE Transactions on, 52, 2759-2772. doi:10.1109/TGRS.2013.2265659.

Sasaki, H., Klein, P., Qiu, B., \& Sasai, Y. (2014). Impact of oceanic-scale interactions on the seasonal modulation of ocean dynamics by the atmosphere. Nat Commun, 5 . URL: http://dx.doi.org/10.1038/ncomms6636.

Stoffelen, A., \& Portabella, M. (2006). On bayesian scatterometer wind inversion. Geoscience and Remote Sensing, IEEE Transactions on, 44, 1523-1533. doi 10.1109/ TGRS.2005.862502.

Torres, R., Snoeij, P., Geudtner, D., Bibby, D., Davidson, M., Attema, E., Potin, P., Rommen, B., Floury, N., Brown, M., Traver, I. N., Deghaye, P., Duesmann, B., Rosich, B., Miranda, N., Bruno, C., L'Abbate, M., Croci, R., Pietropaolo, A., Huchler, M., \& Rostan, F. (2012). GMES Sentinel-1 mission. Remote Sensing of Environment, 120, 9-24. URL:/http://www.sciencedirect.com/science/article/ pii/S0034425712000600 doi:http://dx.doi.org/10.1016/j.rse.2011.05.028.

Wentz, F. J., \& Smith, D. K. (1999). A model function for the ocean-normalized radar cross section at $14 \mathrm{GHz}$ derived from NSCAT observations. Journal of Geophysical Research: Oceans, 104, 11499-11514. URL: http://dx.doi.org/10.1029/98JC02148. doi $10.1029 / 98 J C 02148$.

Wurtele, M. G., Woiceshyn, P. M., Peteherych, S., Borowski, M., \& Appleby, W. S. (1982). Wind direction alias removal studies of SEASAT scatterometer-derived wind fields. Journal of Geophysical Research: Oceans, 87, 3365-3377. URL: http://dx. 
doi.org/10.1029/JC087iC05p03365. doi:10.1029/JC087iC05p03365

Zhang, B., Perrie, W., Vachon, P. W., Li, X., Pichel, W. G., Guo, J., \& He, Y. (2012). Ocean vector winds retrieval from C-band fully polarimetric SAR measurements. IEEE Transactions on Geoscience and Remote Sensing, 50, 4252-4261. doi 10.1109/TGRS. 2012.2194157 . 


\section{Appendix A. Ambiguity Selection}

The ambiguity selection normally uses additional information (typically from numerical weather/marine prediction models) and spatial consistency constraints, to select one of the ambiguous solutions [e.g. Wurtele et al. 1982; Portabella \& Stoffelen 2004].

The algorithm proposed here has been designed to find the optimal solution from among the four ambiguous solutions without having to refer to the true wind or current vectors used to generate the Monte-Carlo data. It is well suited for a Monte-Carlo simulation where the 2000 observations correspond to identical current and wind conditions. If not designed for operational purpose, this algorithm however gives useful information on the capability of the system to separate the ambiguous solutions.

(a) The 2000 observations have been split randomly into 20 groups of 100 observations. Using 10, 15, 20, 30 or 50 groups does not change the results by more than e.g. $<0.01 \mathrm{~m} / \mathrm{s}$ on current velocity.

(b) For each group, the four ambiguous solutions of the 100 observations are clustered in four classes using the standard matlab's 'cluster' function in the solution space (wind and current vectors, i.e. 4-dimension space).

(i) For each solution, the probability of an incorrect fit is calculated with the Pearson's chi-squared test from the cost function value;

(ii) The average of the probability value of the individual solutions within each of the four classes is calculated;

(iii) The class with the smallest probability value average is selected;

(iv) median, interquartile range (IQR), extrema (minimum and maximum) of the 100 observations within the selected class are calculated.

(c) at this stage, 20 groups of 100 solutions with no ambiguity have been selected, but not all 20 groups have picked the correct cluster. The next step aims to find the few groups which have not picked the correct cluster and to force them to choose the ambiguity closest to the center (median) of the 2000 individual solutions:

(i) median, IQR of the 2000 selected solutions of the 2000 observations are calculated; 
(ii) the consistency of the optimal solution is tested between the 20 groups. A selected class of some of the 20 groups is set as outlier if:

- the center (median) for a group of 100 solutions is outside the typical position of the 2000 solutions. The typical position is characterized by a Tukey box (defined below) of the 2000 solutions position;

- the spread (IQR) for a group of 100 solutions is larger than the typical spread of the 20 groups. The typical spread is characterized by an extended Tukey box (defined below) of the IQR of the 20 groups;

- same as above but for a spread defined by the extrema;

(iii) for outlier groups, the class selected on step (b)-(iii) is revisited and is chosen to be the class closest to the global median; step (c) is repeated until convergence (no outliers found anymore; one or two iterations).

A Tukey box is delimited by 1.5 IQR of the data below the lower quartile and 1.5 IQR above the third quartile. The extended Tukey box uses 3 IQR instead of 1.5 IQR. 